\title{
Kompensasi, Motivasi dan Budaya Terhadap Kinerja Karyawan
}

\author{
Iren Kurnia Zebua1, Maya Agustina Tanjung², Josua Evan Lumban Toruan ${ }^{3}$, Devi Novita \\ Pasaribu4
}

1,2,3,4 Program Studi Manajemen, Fakultas Ekonomi Universitas Prima Indonesia, Indonesia

Kata
kunci:
Kompensasi;
Motivasi;
Budaya;
Kinerja
Karyawan

\begin{abstract}
Keywords:

Motivation;

Culture;

Employee

Performance

Abstract: The performance of employees in the company has decreased a lot, this is due to compensation that is not in accordance with what is sacrificed to the company. The purpose of this study was to analyze the effect of compensation, work motivation and culture on employee performance. The research model used is quantitative research methods. The population in this study amounted to all 70 employees. The sampling method with Non-Probability sampling is a saturated sample of 30 people. The data were analyzed using the classical assumption test, multiple linear regression analysis, analysis of determination, simultaneous significance test ( $F$ test) and partial significance test (t-test). The results showed that the value of tcount (3.447) > ttable (1.981) and significant obtained $0.001<0.05$, meaning that compensation has a positive and significant effect on employee performance. The value of tcount (3.009) > ttable (1.981) and the significance obtained is $0.003<0.05$, meaning that partially motivation has a positive and significant effect on employee performance. The value of tcount (3.005) > ttable (1.981) and the significance obtained is $0.003<0.05$, meaning that partially culture has a positive and significant effect on employee performance. So, compensation, work motivation and culture on employee performance. The implications of this research can provide an evaluation in improving employee performance.
\end{abstract}

\begin{abstract}
Abstrak: Kinerja karyawan pada perusahaan banyak mengalami penurunan. Hal ini disebabkan oleh kompensasi yang tidak sesuai dengan yang dikorbankan kepada perusahaan. Tujuan penelitian ini adalah untuk menganalisis pengaruh kompensasi, motivasi kerja, dan budaya terhadap kinerja pegawai. Model penelitian yang digunakan adalah metode penelitian kuantitatif. Populasi dalam penelitian ini berjumlah seluruh 70 karyawan. Metode pengambilan sampel dengan Non-Probability sampling ialah sampel jenuh yang berjumlah 30 orang. Data dianalisis dengan menggunakan uji asumsi klasik, analisis regresi linier berganda, analisis determinasi, uji signifikansi simultan (F-test) dan uji signifikansi parsial (t-test). Hasil penelitian menunjukan nilai $t_{\text {hitung }}(3,447)>t_{\text {tabel }}(1,981)$ dan signifikan yang diperoleh $0,001<0,05$, berarti Kompensasi berpengaruh positif dan signifikan terhadap Kinerja Karyawan. Nilai $t_{\text {hitung }}(3,009)>t_{\text {tabel }}(1,981)$ dan signifikan yang diperoleh $0,003<0,05$, berarti secara parsial Motivasi berpengaruh positif dan signifikan terhadap Kinerja Karyawan. Nilai thitung $(3,005)>t_{\text {tabel }}(1,981)$ dan signifikan yang diperoleh $0,003<0,05$. Ini berarti bahwa secara parsial budaya berpengaruh positif dan signifikan terhadap kinerja karyawan. Ini berarti bahwa kompensasi, motivasi kerja dan budaya berpengaruh terhadap kinerja pegawai. Implikasi penelitian ini dapat memberikan evaluasi dalam meningkatkan kinerja karyawan.
\end{abstract}

Alamat Korespondensi:

E-mail: zebua989@gmail.com (Zebua)

\section{Pendahuluan}

Keberhasilan suatu perusahaan sangat bergantung pada tingkat kinerja pegawai. Kinerja merupakan hasil kerja secara kualitas dan kuantitas yang dicapai oleh seseorang pegawai dalam melaksanakan tugasnya sesuai dengan tanggung jawab yang diberikan. (Effendi \& Yogie, 2019; Farhah et al., 2020; Rachmawati, 2017). Suatu perusahaan yang memiliki karyawan dengan

$\begin{array}{ll}\text { History: } & \\ \text { Received } & \text { : } 40 \text { Mei } 2021 \\ \text { Revised } & : 31 \text { Mei } 2021 \\ \text { Accepted } & \text { : 06 Juli } 2021 \\ \text { Published } & \text { : 25 Juli } 2021\end{array}$

Publisher: Undiksha Press

Licensed: This work is licensed under a Creative Commons Attribution 3.0 License

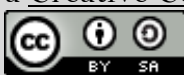


kinerjanya baik besar kemungkinannya kinerja perusahaan tersebut juga baik, sehingga dalam hal ini terdapat hubungan yang sangat erat antara kinerja individu (karyawan) dan kinerja perusahaan (Aini Kusniawati, 2019; Jufrizen, 2017). Salah satu indikator utama dalam pencapaian SDM yang unggul dan berdaya saing global adalah kinerja SDM/aparatur. Sumber daya manusia merupakan salah satu bagian dari kemajuan ilmu pengetahunan, teknologi, serta ilmu manajemen yang lebih berfokus kepada pengaturan peranan sumber daya manusia di dalam suatu organisasi. Manajemen perusahaan dapat mengambil berbagai langkah yang diperlukan agar dapat meningkatkan kinerja yang sesuai dengan harapan perusahaan.

Namun kenyataannya, kinerja karyawan pada perusahaan banyak mengalami penurunan (Cesilia et al., 2018; Nugraha \& Tjahjawati, 2018; Riyadi, 2015; Rofiliana \& Rofiuddin, 2021). Selain itu, motivasi kerja karyawan menurun yang disebabkan oleh berbagai faktor (Hardono, Haryono, 2017; Purwanto, 2020). Berdasarkan hasil wawancara dan studi dokumentasi yang diperoleh bahwa terjadinya penurunan kinerja karyawan PT Soci Mas Medan. PT Soci Mas Medan merupakan sebuah industri oleokimia yang produknya berupa gliserin, fatty acid, soap noodles. Penurunan kinerja karyawan ini berdampak pada tidak tercapainya target perusahaan. Permasalahan karyawan PT Soci Mas Medan memperoleh kompensasi yang tidak sesuai dengan apa yang dikorbankan kepada perusahaan. Kenaikan gaji yang kecil, insentif yang diberikan kepada karyawan marketing yang rendah yang tidak sebanding dengan target penjualan yang tinggi, bonus yang diberikan tidak merata, dan uang kerajinan yang diberikan tidak untuk semua bagian, tetapi hanya di beberapa bagian. Motivasi kerja karyawan PT Soci Mas Medan pada perusahaan ini masih rendah seperti minimnya penghargaan kepada karyawan yang memiliki kinerja yang tinggi. Selain minimnya penghargaan, motivasi yang berupa pemberian promosi jabatan juga tidak sering dilakukan, sehingga karyawan tidak semangat dalam bekerja dan tidak berinisiatif bekerja dengan cepat dan tepat.

Permasalahan tersebut disebabkan oleh kompensasi yang diberikan belum sesuai. Kompensasi yang layak menimbulkan semangat individu untuk meningkatkan keahliannya, bahkan memperkuat komitmennya terhadap perusahaan atau organisasi, sehingga dapat meningkatkan kinerja individu dan kinerja perusahaan (Nugraha \& Tjahjawati, 2018; Susanto \& Dian Maha Yoga, 2021). Pemberian kompensasi yang layak dan adil tersebut merupakan kunci dalam upaya mendekati pemberian balas jasa yang layak dan adil. Selain itu, perilaku termotivasi mungkin ditingkatkan apabila manajer memberi pekerja cukup sumber daya untuk melakukan pekerjaan dan memberikan coaching secara efektif (Mutakin, 2015; Susanto \& Dian Maha Yoga, 2021). Kinerja dipengaruhi oleh perilaku taat akan aturan perusahaan. Budaya perusahaan memiliki peranan penting dalam membangun prestasi dan produktivitas kerja para karyawan sehingga mengarahkan perusahaan kepada keberhasilan (Lengkong, 2018; Sularmi \& Apriyanti, 2019).

Penelitian sejalan menyatakan bahwa kompensasi memengaruhi kinerja karyawan. Kompensasi yang diberikan sesuai dapat meningkatkan kinerja karyawannya (Juliningrum, Emmy, 2011; Nugraha \& Tjahjawati, 2018). Selain itu, motivasi memberikan dampak terhadap kinerja karyawan (Nasrih, 2016; Rachmawati, 2017). Budaya usaha juga memberikan pengaruh terhadap kinerja karyawan (Hasan, 2016; Juliningrum, Emmy, 2011; Lengkong, 2018). Perbedaan penelitian ini dengan sebelumnya yaitu perusahaan yang digunakan berbeda. Selain itu, penelitian ini juga menambahkan variabel budaya. Tujuan penelitian ini adalah menganalisis pengaruh kompensasi, motivasi, dan budaya terhadap kinerja karyawan pada PT Soci Mas Medan. Adanya penelitian ini diharapkan dapat membantu perusahaan dalam meningkatkan kinerja karyawannya, sehingga tujuan perusahaan dapat tercapai.

\section{Metode}

Pendekatan penelitian ini dilakukan secara kuantitatif. Populasi dalam penelitian ini berjumlah 168 karyawan. Sampel merupakan bagian dari jumlah dan karakteristik yang dimiliki oleh populasi. Metode pengambilan sampel dengan Non Probability sampling yaitu berjumlah sampel sebanyak 118 karyawan. Penelitian ini dilakukan pada PT Soci Mas Medan yang berlokasi di Jalan Pulau Irian KIM no 2 Medan. Teknik pengumpulan data dalam penelitian ini yaitu wawancara, 
kuesioner, dan dokumen. Analisis penelitian mengunakan analisis regresi linear berganda. Metode kuantitatif berusaha mengukur dan menyelidiki populasi sampel. Cara menentukan sampel dilakukan secara acak. Untuk menguji hipotesis digunakan analisis data yang bersifat kuantitatif. Populasi untuk penelitian ini terdiri dari 70 karyawan PT Pancakarsa Bangun Reksa Dana Medan. Metode pengambilan sampel dengan non-Probability sampling ialah sampel jenuh yang berjumlah 30 orang. Penelitian ini dilakukan di PT Pancakarsa Bangun Reksa yang terletak di Jl. Bintang Terang Km 13.8, Gg Bintang No.95 Medan yang berlangsung pada tanggal 10 Februari 2020 sampai dengan selesai.

Analisis data bersifat kuantitatif dengan tujuan menguji hipotesis yang telah ditentukan. Uji validitas dipakai untuk mengetahui valid atau tidaknya sebuah angket. Apabila pertayaan pada angket bisa memprediksi objek penelitian maka angket dapat dikatakan valid. Uji instrumen digunakan 2 prosedur ialah validitas menggunakan validitas menggunakan teknik Bivariate Pearson Product Moment Correlations dan uji validitas menggunakan Alpha Cronbach's. Hasil pengujian instrumen validitas konsisten maka angket/kuesioner tersebut dinyatakan mampu dan dapat diandalkan. Setelah diberikan kepada responden, kuesioner dianalisis dengan uji asumsi klasik terdiri dari uji normalitas, uji multikolinieritas, dan uji heterokedasitas. Uji hipotesis dilakukan dengan analisis regresi linier berganda.

\section{Hasil dan Pembahasan}

\section{Hasil Penelitian}

Uji Normalitas

Pendekatan penelitian ini dilakukan secara kuantitatif. Uji persyaratan analisis pertama dilakukan uji normalitas, hasil uji normalitas ini dapat ditinjau berdasarkan pada grafik histogram sebagaimana di bawah ini.

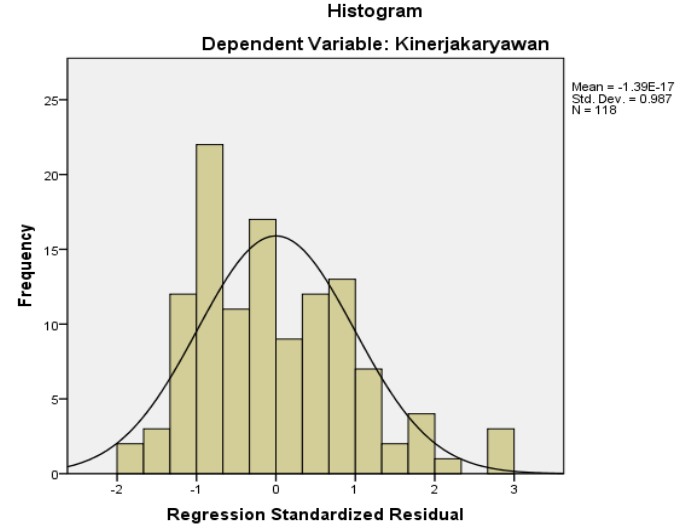

Gambar 1. Grafik histogram uji normalitas

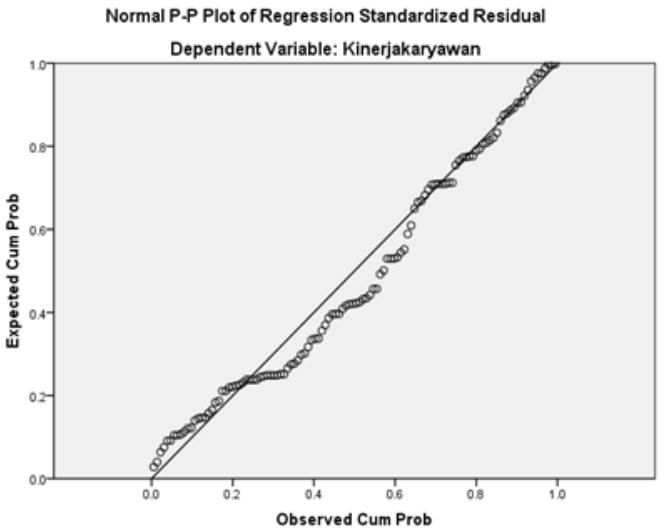

Gambar 2. Grafik Normal P.P Plot Of Regresion Standardized Residul

Grafik histogram menunjukkan data riil membentuk garis kurva cenderung simetri (U) tidak melenceng ke kiri atau pun ke kanan maka dapat dikatakan data berdistribusi normal. Sedangkan grafik normalitas P-P Plot terlihat data menyebar di sekitar garis diagonal yang penyebarannya sebagian besar mendekati garis diagonal. Hal ini berarti bahwa data berdistribusi normal. Berikut ini adalah uji normalitas secara statistik menggunakan Kolmogorov Smirnov. Nilai signifikan 0,165 > 0,05 . Dengan demikian, hasil uji hasil tersebut menunjukkan data berdistribusi normal. Berikut ini merupakan uji multikolinieritas dapat juga dilihat dari nilai tolerance dan variance inflation factor (VIF). Hasil pengujian multikolinearitas disajikan pada Tabel 2. 
Tabel 1. Uji Normalitas Kolmogorov Smirnov

\begin{tabular}{llr}
\hline & One-Sample Kolmogorov-Smirnov Test \\
\hline & & $\begin{array}{r}\text { Unstandardized } \\
\text { Residual }\end{array}$ \\
\hline$N$ & & 118 \\
Normal Parameters & & 0,0000000 \\
& Mean & 8,19503154 \\
Most Extreme Differences & Std. Deviation & 0,103 \\
& Absolute & 0,103 \\
Kolmogorov-Smirnov Z & Positive & $-0,054$ \\
Asymp. Sig. (2-tailed) & Negative & 1,119 \\
\hline a. Test distribution is Normal. & & 0,164 \\
b. Calculated from data. & & \\
\hline
\end{tabular}

Tabel 2. Uji Multikolinearitas

\begin{tabular}{|c|c|c|c|c|c|c|c|c|}
\hline \multicolumn{9}{|c|}{ Coefficients $^{\mathrm{a}}$} \\
\hline \multirow{2}{*}{\multicolumn{2}{|c|}{ Model }} & \multicolumn{2}{|c|}{$\begin{array}{l}\text { Unstandardized } \\
\text { Coefficients }\end{array}$} & \multirow{2}{*}{$\begin{array}{c}\begin{array}{c}\text { Standardized } \\
\text { Coefficients }\end{array} \\
\text { Beta }\end{array}$} & \multirow[b]{2}{*}{$\mathbf{t}$} & \multirow[b]{2}{*}{ Sig. } & \multicolumn{2}{|c|}{$\begin{array}{l}\text { Collinearity } \\
\text { Statistics }\end{array}$} \\
\hline & & B & Std. Error & & & & Tolerance & VIF \\
\hline \multirow[t]{4}{*}{1} & (Constant) & 2,810 & 2,509 & & 1,120 & 0,265 & & \\
\hline & Kompensasi & 0,256 & 0,074 & 0,285 & 3,447 & 0,001 & 0,870 & 1,150 \\
\hline & Motivasi & 0,308 & 0,102 & 0,249 & 3,009 & 0,003 & 0,869 & 1,150 \\
\hline & Budaya & 0,286 & 0,095 & 0,248 & 3,005 & 0,003 & 0,875 & 1,143 \\
\hline
\end{tabular}

a. Dependent Variable: Kinerjakaryawan

Nilai tolerance $>0,1$ dan nlai VIF untuk variabel variabel $<10$ berarti bahwa dalam penelitian ini tidak terjadi multikolinearitas. Selanjutnya, uji heteroskedastisitas bertujuan menguji perbedaan variance residual suatu periode pengamatan ke periode pengamatan yang lain. Ada beberapa cara untuk mendeteksi ada atau tidaknya heteroskedastisitas.

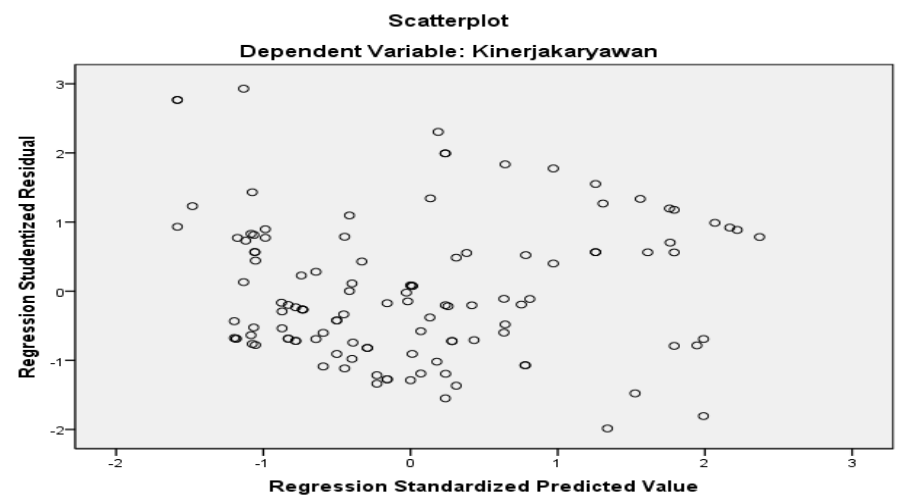

Gambar 3. Uji Heteroskedastisitas

Grafik menunjukkan titik-titik menyebar dengan pola yang tidak jelas baik di atas maupun di bawah angka nol (0) pada sumbu $Y$, tidak berkumpul di satu tempat, sehingga dari grafik scatterplot menunjukkan tidak terjadi heteroskedastisitas pada model regresi. Menunjukkan nilai signifikan > 0,05 yaitu kompensasi $(0,547)$, motivasi $(0,942)$ dan budaya $(0,640)$ bahwa tidak terjadi masalah heteroskedastisitas. Pengujian hipotesis yang digunakan dalam penelitian adalah dengan menggunakan analisis regresi linier berganda. Model regresi yang digunakan adalah sebagai berikut . 
Tabel 3. Uji Gletjer

\begin{tabular}{|c|c|c|c|c|c|c|}
\hline \multicolumn{7}{|c|}{ Coefficients } \\
\hline \multirow{2}{*}{\multicolumn{2}{|c|}{ Model }} & & & \multirow{2}{*}{$\begin{array}{c}\begin{array}{c}\text { Standardized } \\
\text { Coefficients }\end{array} \\
\text { Beta }\end{array}$} & \multirow[b]{2}{*}{$\mathrm{t}$} & \multirow[b]{2}{*}{ Sig. } \\
\hline & & B & Std. Error & & & \\
\hline 1 & (Constant) & 5,504 & 1,454 & & 3,787 & 0,000 \\
\hline & Kompensasi & 0,026 & 0,043 & 0,061 & 0,605 & 0,547 \\
\hline & Motivasi & $-0,004$ & 0,059 & $-0,007$ & $-0,073$ & 0,942 \\
\hline & Budaya & 0,026 & 0,055 & 0,047 & 0,468 & 0,640 \\
\hline
\end{tabular}

Tabel 4. Hasil Analisis Regresi Linear Berganda

\begin{tabular}{|c|c|c|c|c|c|c|c|c|}
\hline \multicolumn{9}{|c|}{ Coefficients } \\
\hline \multirow{2}{*}{\multicolumn{2}{|c|}{ Model }} & \multicolumn{2}{|c|}{$\begin{array}{l}\text { Unstandardized } \\
\text { Coefficients }\end{array}$} & \multirow{2}{*}{$\begin{array}{c}\text { Standardized } \\
\text { Coefficients } \\
\text { Beta } \\
\end{array}$} & \multirow[b]{2}{*}{$\mathbf{t}$} & \multirow[b]{2}{*}{ Sig. } & \multicolumn{2}{|c|}{$\begin{array}{l}\text { Collinearity } \\
\text { Statistics }\end{array}$} \\
\hline & & B & Std. Error & & & & Tolerance & VIF \\
\hline \multirow[t]{4}{*}{1} & (Constant) & 2,810 & 2,509 & & 1,120 & 0,265 & & \\
\hline & Kompensasi & 0,256 & 0,074 & 0,285 & 3,447 & 0,001 & 0,870 & 1,150 \\
\hline & Motivasi & 0,308 & 0,102 & 0,249 & 3,009 & 0,003 & 0,869 & 1,150 \\
\hline & Budaya & 0,286 & 0,095 & 0,248 & 3,005 & 0,003 & 0,875 & 1,143 \\
\hline
\end{tabular}

$$
Y=2,810+0,256 X_{1}+0,308 X_{2}+0,286 X_{3}+e
$$

Penjelasan regresi linier berganda di atas adalah konstanta sebesar 2,810 yang menyatakan bahwa jika tidak ada atau konstan maka variabel kompensasi, motivasi kerja, dan budaya kinerja karyawan sebesar 2,810 satuan. Koefisien regresi variabel kompensasi sebesar 0,256 dan bernilai positif. Hal ini menyatakan bahwa apabila setiap kenaikan variabel kompensasi 1 satuan akan meningkatkan variabel kinerja karyawan sebesar 0,256 satuan dengan anggapan variabel lainnya tetap. Koefisien regresi variabel motivasi kerja sebesar 0,308 dan bernilai positif. Hal ini menyatakan bahwa apabila setiap kenaikan variabel motivasi kerja 1 satuan akan meningkatkan variabel kinerja karyawan sebesar 0,308 satuan dengan anggapan variabel lainnya tetap. Koefisien regresi variabel budaya organisasi sebesar 0,286 dan bernilai positif. Hal ini menyatakan bahwa apabila setiap kenaikan variabel budaya 1 satuan akan meningkatkan variabel terikat kinerja karyawan sebesar 0,286 satuan dengan anggapan variabel lainnya tetap. Berikut hasil koefisien determinasi disajikan pada tabel 5 .

Tabel 5. Uji Koefisien Determinasi

\begin{tabular}{lccccc}
\hline \multicolumn{5}{c}{ Model Summary $^{\mathbf{b}}$} \\
\hline Model & $\mathbf{R}$ & R Square & Adjusted R Square & $\begin{array}{c}\text { Std. Error of the } \\
\text { Estimate }\end{array}$ \\
\hline dimension0 & 1 & 0,567 & 0,322 & 0,304 & 8,302 \\
\hline
\end{tabular}

Hasil uji koefisien determinasi diperoleh nilai Adjusted $R$ Square sebesar 0,304. Hal ini berarti $30,4 \%$ dari variasi variabel kinerja karyawan yang dapat dijelaskan oleh variasi variabel kompensasi, motivasi kerja, dan budaya sedangkan sisanya sebesar $69,6 \%(100 \%-30,4 \%)$ dijelaskan oleh variabel lain yang tidak diteliti pada penelitian ini, seperti kompetensi kerja, stres kerja, analisa jabatan dan sebagainya. Berikut hasil pengujian hipotesis secara simultan (Uji F) disajikan pada Tabel 6. 
Tabel 6. Uji Simultan (Uji F)

\begin{tabular}{llrrrrr}
\hline \multicolumn{7}{c}{ ANOVA } \\
\hline Model & & Sum of Squares & \multicolumn{1}{c}{ df } & Mean Square & F & \multicolumn{1}{c}{ Sig. } \\
\hline 1 & Regression & 3728,213 & 3 & 1242,738 & 18,030 & 0,000 \\
& Residual & 7857,549 & 114 & 68,926 & & \\
& Total & 11585,763 & 117 & & & \\
\hline
\end{tabular}

Hasil pengujian diperoleh nilai $F_{\text {hitung }}(22,120)>F_{\text {tabel }}(2,68)$ dan probabilitas signifikansi $0,000<0,05$, berarti bahwa Ha diterima dam Ho ditolak yaitu secara simultan kompensasi, motivasi, dan budaya berpengaruh positif dan signifikan terhadap kinerja karyawan pada PT Soci Mas Medan. Berikut hasil pengujian hipotesis secara Parsial.

Tabel 7. Uji Parsial (Uji t)

\begin{tabular}{|c|c|c|c|c|c|c|c|c|}
\hline \multicolumn{9}{|c|}{ Coefficients $^{\mathrm{a}}$} \\
\hline \multirow{2}{*}{\multicolumn{2}{|c|}{ Model }} & \multicolumn{2}{|c|}{$\begin{array}{l}\text { Unstandardized } \\
\text { Coefficients }\end{array}$} & \multirow{2}{*}{$\begin{array}{c}\begin{array}{c}\text { Standardized } \\
\text { Coefficients }\end{array} \\
\text { Beta } \\
\end{array}$} & \multirow[b]{2}{*}{$t$} & \multirow[b]{2}{*}{ Sig. } & \multicolumn{2}{|c|}{$\begin{array}{l}\text { Collinearity } \\
\text { Statistics }\end{array}$} \\
\hline & & B & Std. Error & & & & Tolerance & VIF \\
\hline \multirow[t]{4}{*}{1} & (Constant) & 2,810 & 2,509 & & 1,120 & 0,265 & & \\
\hline & Kompensasi & 0,256 & 0,074 & 0,285 & 3,447 & 0,001 & 0,870 & 1,150 \\
\hline & Motivasi & 0,308 & 0,102 & 0,249 & 3,009 & 0,003 & 0,869 & 1,150 \\
\hline & Budaya & 0,286 & 0,095 & 0,248 & 3,005 & 0,003 & 0,875 & 1,143 \\
\hline
\end{tabular}

Pengujian hipotesis secara parsial diperoleh nilai $t_{\text {hitung }}(3,447)>t_{\text {tabel }}(1,981)$ dan signifikan yang diperoleh $0,001<0,05$ yang berarti bahwa Ha diterima dam Ho ditolak yaitu secara parsial Kompensasi berpengaruh positif dan signifikan terhadap kinerja karyawan pada PT Soci Mas Medan. Pengujian hipotesis secara parsial diperoleh nilai $t_{\text {hitung }}(3,009)>t_{\text {tabel }}(1,981)$ dan signifikan yang diperoleh $0,003<0,05$ yang berarti bahwa Ha diterima dam Ho ditolak yaitu secara parsial. Motivasi berpengaruh positif dan signifikan terhadap kinerja karyawan pada PT Soci Mas Medan. Pengujian hipotesis secara parsial diperoleh nilai $t_{\text {hitung }}(3,005)>t_{\text {tabel }}(1,981)$ dan signifikan yang diperoleh 0,003 $<0,05$ yang berarti bahwa Ha diterima dam Ho ditolak yaitu secara parsial budaya berpengaruh positif dan signifikan terhadap kinerja karyawan pada PT Soci Mas Medan.

\section{Pembahasan}

Berdasarkan hasil penelitian temuan pertama, kompensasi berpengaruh positif dan signifikan terhadap kinerja karyawan pada PT Soci Mas Medan. Pemberian kompensasi yang layak dan adil tersebut merupakan kunci dalam upaya mendekati pemberian balas jasa yang layak dan adil (Nugraha \& Tjahjawati, 2018; Rinaldi \& Cheisviyanny, 2015). Permasalahan karyawan PT Soci Mas Medan memperoleh kompensasi yang tidak sesuai dengan apa yang dikorbankan kepada perusahaan. Kenaikan gaji yang kecil, insentif yang diberikan kepada karyawan marketing yang rendah yang tidak sebanding dengan target penjualan yang tinggi, bonus yang diberikan tidak merata, dan uang kerajinan yang diberikan tidak untuk semua bagian, tetapi hanya di beberapa bagian. Kompensasi yang layak menimbulkan semangat individu untuk meningkatkan keahliannya bahkan memperkuat komitmennya terhadap perusahaan atau organisasi, sehingga pada akhirnya dapat meningkatkan kinerja individu dan kinerja perusahaan atau organisasi (Izzah \& Ardiani, 2018; Nasir \& Siregar, 2017; Nurhas, 2017). Temuan ini diperkuat dengan temuan sebelumnya yang menyatakan kompensasi memberikan pengaruh terhadap kinerja karyawan (Garaika, 2020; Jufrizen, 2017; Juliningrum, Emmy, 2011; Nugraha \& Tjahjawati, 2018). Semakin tinggi kompensasi yang diterima, maka karyawan akan semakin semangat dalam melaksankan tugas yang diberikan perusahaan, sehingga karyawan menghasilkan prestasi kerja yang baik bagi perusahaan (Gandung \& Suwanto, 2020; Hasan, 2016). 
Temuan kedua, motivasi berpengaruh positif dan signifikan terhadap kinerja karyawan pada PT Soci Mas Medan. Motivasi kerja karyawan PT Soci Mas Medan pada perusahaan ini masih rendah seperti minimnya penghargaan kepada karyawan yang memiliki kinerja yang tinggi. Selain minimnya penghargaan, motivasi dalam berupa pemberian promosi jabatan juga tidak sering dilakukan, sehingga karyawan tidak semangat dalam bekerja dan tidak berinisiatif bekerja dengan cepat dan tepat. Perilaku termotivasi mungkin ditingkatkan apabilal manajer memberi pekerja cukup sumber daya untuk melakukan pekerjaan dan memberikan coaching secara efektif. Temuan ini diperkuat dengan penelitian sebelumnya yang menyatakan motivasi memberikan pengaruh terhadap kinerja karyawan (Farhah et al., 2020; Rachmawati, 2017; Setiawan et al., 2020). Motivasi merupakan suatu dorongan seseorang untuk melakukan serangkaian kegiatan yang mengarah tercapainya tujuan tertentu (Supriyono, 2017; Wachidah, 2019). Karyawan yang memiliki keinginan kuat agar tercapai tujuan perusahaan dan ingin tetap dalam organisasi akan memiliki motivasi kerja yang tinggi agar keinginannya tercapai. Motivasi adalah sesuatu yang mulai gerakan, sesuatu yang mulai bertindak dengan cara tertentu (Kridharta \& Rusdianti, 2017; Supriyono, 2017)

Temuan ketiga yaitu budaya berpengaruh positif dan signifikan terhadap kinerja karyawan pada PT Soci Mas Medan. Budaya organisasi PT Soci Mas Medan yang masih lemah tercermin dari peningkatan pelanggaran aturan yang dilakukan oleh karyawan berupa penyelesaian pekerjaan yang tidak memenuhi aturan dan tidak memerhatikan SOP yang berlaku di dalam perusahaan. Selain itu, j sistem manajemen yang rumit dan menyulitkan karyawan dalam permintaan izin sehingga memicu budaya organisasi dalam perusahaan yang lemah. Budaya perusahaan memiliki peranan penting dalam membangun prestasi dan produktivitas kerja para karyawan sehingga mengarahkan perusahaan kepada keberhasilan (Juliningrum, Emmy, 2011; Lengkong, 2018; Nurhas, 2017). Budaya organisasi akan membentuk komitmen karyawan.Ka komitmen karyawan baru akan memengaruhi kinerja karyawan, sehingga komitmen karyawan sangat penting untuk diperhatikan, yang akan dibentuk melalui Bbdaya organisasi yang diciptakan oleh perusahaan (Nugroho, 2019; Sularmi \& Apriyanti, 2019).

\section{Simpulan}

Hasil penelitian menunjukkan adanya pengaruh kompensasi, motivasi, dan budaya terhadap kinerja karyawan pada PT Soci Mas Medan. Kinerja karyawan meningkat apabila variabel kompensasi, motivasi, dan budaya kerja yang dimiliki pegawai meningkat. Keterbatasan penelitian ini adalah pengamatan hanya dilakukan pada satu perusaha. Dari segi jumlah sampel yang digunakan dalam penelitian ini masih sedikit, sehingga diharapkan bagi peneliti lain agar menggunakan perusahaan yang lebih besar dengan jumlah sampel penelitian yang lebih luas. Dengan asil penelitian lebih teruji kehandalannya. Implikasi penelitian diharapkan dapat membantu perusahaan dalam meningkatkan kinerja karyawannya.

\section{Daftar Pustaka}

Aini Kusniawati, N. (2019). Pengaruh Lingkungan Kerja dan Disiplin Kerja terhadap Kinerja Karyawan pada PT Gapuraning Rahayu Ciamis. Jurnal IImu Manajemen, 1(1), 49-70.

Cesilia, K. A., Tewal, B., \& Tulung, J. E. (2018). Pengaruh Disiplin Kerja, Perencanaan Karier, dan Kompetensi terhadap Kinerja Karyawan Kantor Pelayanan Pajak (KPP) Pratama Manado. Jurnal EMBA: Jurnal Riset Ekonomi, Manajemen, Bisnis Dan Akuntansi, 6(1), 426-434. https://doi.org/10.35794/emba.v6i1.19153.

Effendi, M., \& Yogie, F. (2019). Pengaruh Motivasi dan Disiplin Kerja terhadap Kinerja Karyawan. Journal of Management and Bussines (JOMB), 1(1), 88-98. https://doi.org/10.31539/jomb.v1i1.654.

Farhah, A., Ahiri, J., \& Ilham, M. (2020). Pengaruh Motivasi Kerja dan Disiplin Kerja terhadap Kinerja Karyawan. Jurnal Online Program Studi Pendidikan Ekonomi, 5(1), 1. https://doi.org/10.36709/jopspe.v5i1.13326. 
Gandung, M., \& Suwanto, S. (2020). Analisis Pengaruh Kompensasi dan Gaya Kepemimpinan terhadap Kinerja Karyawan Pada PT Surya Rasa Loka Jaya di Jakarta Barat. JENIUS (Jurnal Ilmiah Manajemen Sumber Daya Manusia), 3(3), 236 - 245. https://doi.org/10.32493/JJSDM.v3i3.4861.

Garaika, G. (2020). Pengaruh Kompensasi, Motivasi Kerja dan Kepuasan Kerja sebagai Variabel Intervening terhadap Kinerja. Jurnal Ilmiah Manajemen Dan Bisnis, 21(1), 28-41. https://doi.org/10.30596/jimb.v21i1.4181.

Hardono, Haryono, A. Y. (2017). Kepemimpinan Kepala Sekolah, Supervisi Akademik, dan Motivasi Kerja dalam Meningkatkan Kinerja Guru. Jurnal Unnes, 6(1), 1-8.

Hasan, S. (2016). Pengaruh Budaya Organisasi, Kompensasi, Motivasi, Kepemimpinan terhadap Kinerja Karyawan Bandara Internasional Sultan Aji Muhammad Sulaiman. Jurnal Benefita, 1(3), 134-145. https://doi.org//10.22216/jbe.v1i3.1076.

Izzah, N., \& Ardiani, I. (2018). Pengaruh Kompensasi Dan Disiplin Kerja terhadap Produktivitas Kerja Karyawan pada Mechanical Division PT Mulia Makmur Elektrikatama. Majalah IImiah Bijak, 13(2), 210-222. https://doi.org/10.31334/bijak.v13i2.78.

Jufrizen, J. (2017). Efek Mediasi Kepuasan Kerja pada Pengaruh Kompensasi terhadap Kinerja Karyawan. Jurnal Ilmiah Manajemen Dan Bisnis, 17(01), 34-53. https://doi.org/10.30596\%2Fjimb.v17i1.1209.

Juliningrum, Emmy, A. S. (2011). Pengaruh Kompensasi, Budaya Organisasi, terhadap Motivasi Kerja dan Kinerja Pegawai Emmy. 66.

Kridharta, D., \& Rusdianti, E. (2017). Analisis Pengaruh Karakteristik Individu, Komitmen Organisasi, dan Kepuasan Kerja terhadap Kinerja Karyawan dengan Motivasi sebagai Variabel Intervening. Jurnal Riset Ekonomi Dan Bisnis, 10(3), 232. https://doi.org/10.26623/jreb.v10i3.882.

Lengkong, V. P. K. (2018). Pengaruh Komitmen Organisasi dan Budaya Organisasi terhadap Kinerja Pegawai di BKDPSDA di Kabupaten Halmahera Utara. Jurnal EMBA: Jurnal Riset Ekonomi, Manajemen, Bisnis Dan Akuntansi, 6(4), 1968-1977. https://doi.org/10.35794/emba.v6i4.20918.

Mutakin, T. Z. (2015). Pengaruh Kompetensi, Kompensasi, dan Latar Belakang terhadap Kinerja Guru. Formatif: Jurnal Ilmiah Pendidikan MIPA, 3(2), 145-156. https://doi.org/10.30998/formatif.v3i2.122.

Nasir, M., \& Siregar, M. R. (2017). Pengaruh Pelatihan, Kompensasi, dan Disiplin Kerja terhadap Prestasi Kerja Karyawan di Kantor PLN (Persero) Banda Aceh. Jurnal Ilmiah Mahasiswa Ekonomi Manajemen, 2(1), 104-117. https://doi.org/10.24815/jimen.v2i1.2033.

Nasrih, M. L. (2016). Analisis Hubungan Kepuasan Kerja terhadap Prestasi Kerja Karyawan. Allqtishad: Journal of Islamic Economics, 2(1). https://doi.org/10.15408/aiq.v2i1.2477.

Nugraha, A., \& Tjahjawati, S. S. (2018). Pengaruh Kompensasi terhadap Kinerja Karyawan. Jurnal Riset Bisnis Dan Investasi, 3(3), 24. https://doi.org/10.35697/jrbi.v3i3.942.

Nugroho, R. E. (2019). Pengaruh Gaya Kepemimpinan Transformasional Stress Kerja dan Budaya Organisasi terhadap Kinerja Karyawan Kontrak Proyek. Jurnal IImiah Manajemen, 9(2), 341 354. https://doi.org/10.22441/mix.2019.v9i2.007.

Nurhas, F. A. (2017). Pengaruh Budaya Organisasi, Kepemimpinan, dan Kompensasi melalui Motivasi Kerja terhadap Kinerja Pegawai. JMM, 13(2), 896-908. https://doi.org/10.29406/jmm.v13i2.723.

Purwanto, A. (2020). Studi Eksplorasi Dampak WFH terhadap Kinerja Guru. Journal of Education, Psychology and Counseling, 2(1), 92-100.

Rachmawati, R. W. (2017). Pengaruh Pelatihan dan Motivasi Kerja terhadap Kinerja Karyawan Pt. Bank Bjb Kantor Cabang Suci Bandung. Jurnal Manajemen Dan Pemasaran Jasa, 9(1), 1. https://doi.org/10.25105/jmpj.v9i1.802.

Rinaldi, \& Cheisviyanny, C. (2015). Pengaruh Profitabilitas, Ukuran Perusahaan, dan Kompensasi Rugi Fiskal terhadap Tax Avoidance ( Studi Empiris pada Perusahaan Manufaktur yang Terdaftar di BEI Tahun 2010-2013 ). Seminar Nasional Ekonomi Manajemen Dan Akuntansi (Snema) 
Fakultas Ekonomi Universitas Negeri Padang, 472-483.

Riyadi, B. A. (2015). Pengaruh Pengalaman Kerja terhadap Kinerja Karyawan pada Toko Emas Semar Nganjuk. Jurnal Equilibrium, 3(1), 49-61. https://doi.org/10.25273/equilibrium.v3i1.637.

Rofiliana, L., \& Rofiuddin, M. (2021). Faktor-faktor yang Memengaruhi Kinerja Karyawan Bank Syariah Indonesia. Journal of Management and Digital Business, 1(1), 1-12. https://doi.org/10.53088/jmdb.v1i1.26.

Setiawan, A. A. K. A., Sujana, I. W., \& Ari, N. N. (2020). Pengaruh Self Efficacy dan Motivasi terhadap Kinerja Karyawan pada Pt Adi Sarana Armada Tbk Badung. 1(2), 31-40.

Sularmi, L., \& Apriyanti, N. H. (2019). Pengaruh Budaya Organisasi dan Disiplin terhadap Kinerja Karyawan pada PT Mega Perintis Tbk. JENIUS (Jurnal Ilmiah Manajemen Sumber Daya Manusia), 3(1), 124-139. https://doi.org/10.32493/jjsdm.v3i1.3373.

Supriyono, A. (2017). Pengaruh Kompetensi Pedagogik, Profesional, dan Motivasi Kerja terhadap Kinerja Guru Sekolah Dasar. Jurnal Pendidikan, 18(2), 1-12. https://doi.org/10.33830/jp.v18i2.269.2017.

Susanto, I. K., \& Dian Maha Yoga, G. (2021). Pengaruh Motivasi, Kompensasi, dan Disiplin Kerja terhadap Prestasi Kerja Karyawan di Puri Sebali Resort \& Spa Gianyar. Jurnal Manajemen, Kewirausahaan Dan Parwisata, 1(2), 618-629. https://doi.org/10.32795/widyaamrita.v1i2.1317.

Wachidah, N. (2019). Pengaruh Sikap Inovatif , Kedisiplinan dan Motivasi Kerja terhadap Kinerja Guru SMP Negeri. Journal of Educational Evaluation Studies (JEES), 1(1), 57-63. 